Check for updates

Cite this: J. Mater. Chem. C, 2020 8, 15377

Received 16th July 2020,

Accepted 7th September 2020

DOI: $10.1039 / \mathrm{dOtc03359f}$

rsc.li/materials-c

\section{Photochromism in Ruddlesden-Popper copper-based perovskites: a light-induced change of coordination number at the surface $\dagger$}

\author{
B. G. H. M. Groeneveld, H. Duim, S. Kahmann, (D) O. De Luca, \\ E. K. Tekelenburg, (D) M. E. Kamminga, L. Protesescu, (D) G. Portale, \\ G. R. Blake, (D) P. Rudolf (D) and M. A. Loi (D)*
}

\begin{abstract}
Ruddlesden-Popper organic-inorganic hybrid copper-based perovskites have been studied for decades owing to a variety of interesting properties, such as thermochromism and piezochromism, and the mechanisms behind these phenomena have been explained. Another possible property of these materials that has seldomly been investigated is photochromism. In this work, the photochromic properties of bis(phenethylammonium) tetrachlorocuprate (also known as phenethylammonium copper chloride) are reported for the first time. This material has attracted scientific interest owing to the fact that it shows both ferroelectric and ferromagnetic behavior. This work highlights the difference in stability between two Ruddlesden-Popper copper-based perovskites - with phenethylammonium (PEA) or methylammonium (MA) as the cations - during external stimuli. Various techniques, such as Raman and X-ray photoelectron spectroscopy, and grazing-incidence wide-angle $X$-ray scattering, combined with optical studies, were used to investigate the underlying photochemical processes at a molecular level. It is found that for the PEA compound, ultraviolet illumination causes a color change from yellow to brown. This is the result of two independent events, namely a $\mathrm{Cu}^{2+}$ reduction reaction and a transition from an octahedral copperchloride structure to square-planar $\mathrm{CuCl}_{4}{ }^{2-}$. After illumination, the material (brown color) is unstable in air, which is evident from a color change back to yellow. Interestingly, the similar compound bis(methylammonium) tetrachlorocuprate does not display photochromic behavior, which is attributed to the different nature of the two organic cations.
\end{abstract}

\section{Introduction}

The family of Ruddlesden-Popper organic-inorganic hybrid perovskites with the structural formula $\mathrm{A}_{2} \mathrm{MX}_{4}$ - where $\mathrm{A}$ is an organic cation with an ammonium group, $\mathbf{M}$ a metal anion (e.g. $, \mathrm{Cu}^{2+}, \mathrm{Pb}^{2+}, \mathrm{Sn}^{2+}, \mathrm{Ge}^{2+}, \mathrm{Mn}^{2+}, \mathrm{Eu}^{2+}$ ) and $\mathrm{X}$ a halide anion encompasses a large selection of materials, each with unique properties. ${ }^{1}$ The halides bind to the metal ions in the form of $\mathrm{MX}_{6}$ octahedra, which are connected by corner-sharing the four in-plane halide ions. ${ }^{2}$ The organic cations (e.g., methylammonium, butylammonium or phenethylammonium) are located in the voids between the octahedra and interact with them via Coulomb interaction and hydrogen bonding, forming an alternating layered two-dimensional structure. ${ }^{1}$ Depending on the structure of the organic cation, the inorganic octahedral framework might not form. An example is given by the difference in

Zernike Institute for Advanced Materials, University of Groningen, Nijenborgh 4, Groningen 9747 AG, The Netherlands. E-mail: m.a.loi@rug.nl

$\dagger$ Electronic supplementary information (ESI) available. See DOI: 10.1039/d0tc03359f structure between bis(phenethylammonium) tetrabromocuprate, $\left(\mathrm{C}_{6} \mathrm{H}_{5} \mathrm{C}_{2} \mathrm{H}_{4} \mathrm{NH}_{3}\right)_{2} \mathrm{CuBr}_{4}$, and bis[methyl(2-phenethyl)ammonium] tetrabromocuprate, $\left(\mathrm{C}_{6} \mathrm{H}_{5} \mathrm{C}_{2} \mathrm{H}_{4} \mathrm{NH}_{2} \mathrm{CH}_{3}\right)_{2} \mathrm{CuBr}_{4}$. The former adopts the octahedral perovskite structure, but the latter has isolated $\mathrm{CuBr}_{4}{ }^{2-}$ anions; the steric hindrance of the methyl group prevents the formation of a perovskite structure because it hinders the formation of hydrogen bonds. The $\mathrm{CuBr}_{4}{ }^{2-}$ structure allows for more space for the organic cation, thereby enabling hydrogen bonding. ${ }^{2,3}$ Typical geometries for these $\mathrm{CuX}_{4}{ }^{2-}$ ions are square-planar $\left(D_{4 \mathrm{~h}}\right.$ symmetry) or distorted tetrahedral $\left(D_{2 \mathrm{~d}}\right.$ symmetry) (see Fig. S1 (ESI $\dagger$ ) for a schematic overview of these geometries). ${ }^{4}$ The difference between these is caused by the strength of the hydrogen bonding of the cation with the halides, where stronger binding leads to a more square-planar character. ${ }^{5}$

The variety in structures for copper halide phases, combined with the presence of Jahn-Teller effects in these $d^{9}$ metal compounds, leads to interesting chemical effects. For instance, the distortion of the $\mathrm{CuX}_{4}{ }^{2-}$ tetrahedral structure and the elongation of certain $\mathrm{Cu}-\mathrm{X}$ bonds in $\mathrm{CuX}_{6}$ octahedra can be attributed to the Jahn-Teller effect. ${ }^{6}$ Of particular interest are 
the copper chloride complexes. These were studied for their piezo- and thermochromism, i.e. the change of color upon pressure and temperature variation, respectively., ${ }^{5-15}$ Their piezochromism is explained by the tilting of the octahedra and reduction of the Jahn-Teller distortion by compressing the long $\mathrm{Cu}-\mathrm{Cl}$ bond. ${ }^{7,8}$ Thermochromism often involves the change in coordination geometry from (nearly) square-planar $\mathrm{CuCl}_{4}{ }^{2-}$ at low temperature to a distorted tetrahedron at higher temperatures, due to the decreased strength of the hydrogen bonding. ${ }^{5,9,10,12,15}$ Riley et al. found that the color change in the thermochromic bis(piperazinium) tetrachlorocuprate could also be induced by laser illumination, but could not establish whether this was really caused by photoexcitation (photochromism) or by local heating due to the laser light. ${ }^{9}$

The work of Pan et al. demonstrated a photochromic effect in $\left(\mathrm{C}_{4} \mathrm{H}_{9} \mathrm{NH}_{3}\right)_{2} \mathrm{CuCl}_{4}$, where a yellow film turned brown after illumination with UV light. ${ }^{16}$ They found little evidence for significant structural changes - infrared spectroscopy indicated a variation in the vibration of the $\mathrm{N}-\mathrm{H} \cdots \mathrm{Cl}$ bond and the long $\mathrm{Cu}-\mathrm{Cl}$ bond - and attributed the effect to a change in charge distribution of the dissymmetric $\mathrm{Cl}-\mathrm{Cu} \cdots \mathrm{Cl}$ bond. In light of the importance of structural changes in the thermochromism described above, we find this conclusion not fully satisfying. In this work we investigated the photochromic properties of a similar material: bis(phenethylammonium) tetrachlorocuprate (also called phenetylammonium copper chloride), or (PEA)2$\mathrm{CuCl}_{4}$. This material, which has an octahedral $\mathrm{CuCl}_{6}$ structure with in-plane Jahn-Teller distortion, displays thermochromism and is a multiferroic due to its coexisting ferromagnetic and ferroelectric order, a property that is highly sought after. ${ }^{14,17}$

We found that $(\mathrm{PEA})_{2} \mathrm{CuCl}_{4}$ changes color upon illumination depending on the atmosphere and the wavelength of the light. Grazing-incidence wide-angle X-ray scattering and Raman spectroscopy revealed that the color change is caused by a structural change in the inorganic framework, which takes place at the surface of the films. Moreover, using X-ray photoelectron spectroscopy we found that the $\mathrm{Cu}^{2+}$ at the surface reduces to $\mathrm{Cu}^{0 /+}$, which might be explained by the formation of elemental copper in the form of clusters or nanoparticles. Air exposure reverses the color change, which is attributed to the absorption of water, leading to a different structure than the pristine material. The lack of photochromism in the similar compound bis(methylammonium) tetrachlorocuprate (or methylammonium copper chloride $)-(\mathrm{MA})_{2} \mathrm{CuCl}_{4}-$ shows that the organic cation plays a decisive role in the process.

\section{Results}

Upon illuminating a yellow film of $(\mathrm{PEA})_{2} \mathrm{CuCl}_{4}$ with ultraviolet (UV, $\lambda=254 \mathrm{~nm}$ ) light in nitrogen atmosphere for 45 minutes, the color of the film changes to brown (see Fig. 1a). This color change is evident from the change in absorbance, which can be seen in Fig. 1b. The pristine material exhibits two absorption peaks in the ultraviolet region, namely the ligand-to-metal
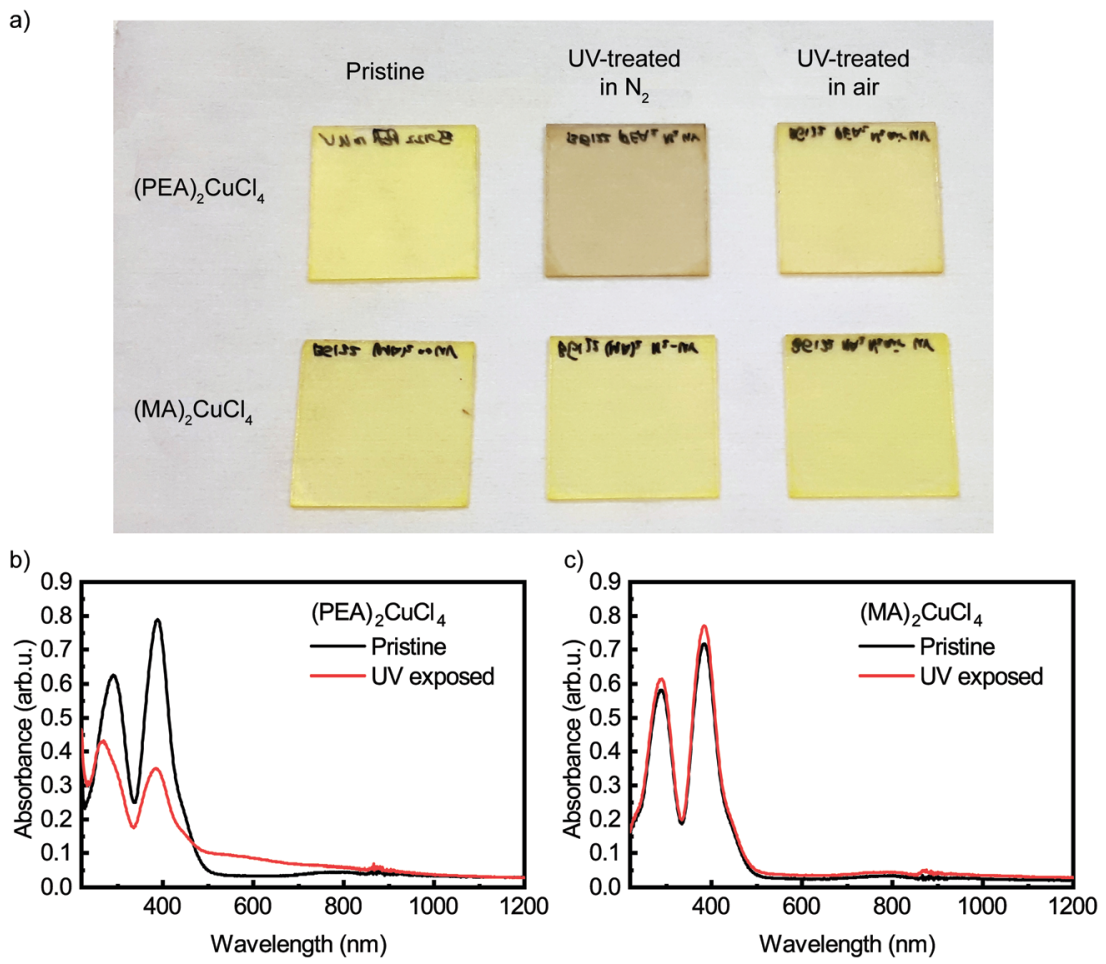

Fig. 1 (a) Photograph of (PEA) $\mathrm{CuCl}_{4}$ (top row) and ( $\mathrm{MA}_{2} \mathrm{CuCl}_{4}$ (bottom row) thin films. These films are pristine (first column), UV-treated in $\mathrm{N}_{2}$ (second column) and UV-treated in air (third column). UV treatment was carried out with $\lambda=254 \mathrm{~nm}$. Thin film absorbance spectra of (b) (PEA) ${ }_{2} \mathrm{CuCl}{ }_{4}$ and (c) $(\mathrm{MA})_{2} \mathrm{CuCl}_{4}$ in the case of a pristine film (black lines) and after 45 minutes of UV illumination in nitrogen environment (red lines). The narrow features between 850 and $900 \mathrm{~nm}$ are measurement artifacts. 
charge transfer transitions at 291 and $388 \mathrm{~nm}$, which is characteristic of Jahn-Teller distorted $\mathrm{CuCl}_{4}{ }^{2-}$ compounds. ${ }^{18}$ After exposure to UV light, the intensity of these peaks decreases and both blueshift - to 266 and $385 \mathrm{~nm}$, respectively. Simultaneously, an additional absorption feature forms between 450 and $800 \mathrm{~nm}$. Pan et al. found very similar behavior when they studied the photochromism in the related compound bis(butylammonium) tetrachlorocuprate. ${ }^{16}$ We also studied $(\mathrm{MA})_{2} \mathrm{CuCl}_{4}$ under UV illumination and found no color change after 45 minutes of exposure. The absorbance spectra of this film before and after UV-treatment can be seen in Fig. 1c. Apart from a small deviation in intensity, the two spectra are nearly identical. This result indicates that the organic cation plays an important role in the photochromism of $(\mathrm{PEA})_{2} \mathrm{CuCl}_{4}$.

Raman spectroscopy has been used to characterize the vibrational modes of various copper chloride complexes. ${ }^{19-21}$ Our Raman spectrum collected from a single crystal of (PEA) $\mathrm{CuCl}_{4}$ (Fig. 2) has clear peaks at 179, 247 and $287 \mathrm{~cm}^{-1}$, and is very similar to the low-frequency regime spectrum reported by Caretta et $a .^{22}$ These peaks are all assigned to vibrational modes of $\mathrm{Cu}-\mathrm{Cl}$ bonds: $\nu_{2}\left(\mathrm{~A}_{1 \mathrm{~g}}\right), \nu_{4}\left(\mathrm{~B}_{2 \mathrm{~g}}\right)$ and $\nu_{1}\left(\mathrm{~A}_{1 \mathrm{~g}}\right)$, respectively. ${ }^{22,23}$ Notably, also prolonged and high intensity exposure to the laser $(\lambda=532 \mathrm{~nm})$ of the Raman microscope converts the pristine material into the brown phase (Fig. S2, ESI $\dagger$ ). We attribute this conversion to absorption taking place due to the small - but non-zero - absorption coefficient at this wavelength, combined with the high-power, focused laser light. This is accompanied by the appearance of a dominant peak at $271 \mathrm{~cm}^{-1}$. Increased laser power accelerates the conversion. This behavior is also observed in thin film samples, for which the Raman signal is naturally weaker (see Fig. S3, ESI $\dagger$ ). Therefore, the color change is not only achieved with UV illumination, but also with focused visible light. Interestingly, the converted brown phase is stable in nitrogen, but not in air. In the latter case the color of the film changes back to yellow (see Fig. S4 (ESI $\dagger$ ) for the absorbance after air exposure), which

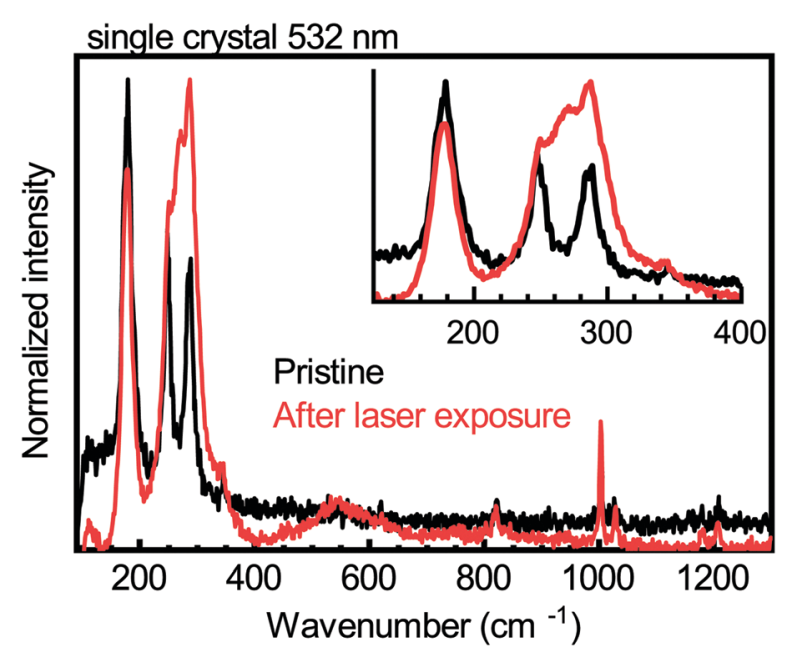

Fig. 2 Raman spectra of a pristine (PEA) ${ }_{2} \mathrm{CuCl}_{4}$ single crystal (black lines) and of the same crystal after $532 \mathrm{~nm}$ laser exposure (red lines). The inset displays a magnification of the low-energy part of the spectra. suggests that the brown phase might be sensitive to oxygen or water. We found that the conversion from the pristine to the brown phase depends on the wavelength and the atmosphere; this is described in the ESI $\dagger$ (see Fig. S5 and the accompanying section).

To investigate whether bulk structural changes occur during the conversion, we studied the pristine and converted films of both $(\mathrm{PEA})_{2} \mathrm{CuCl}_{4}$ and $(\mathrm{MA})_{2} \mathrm{CuCl}_{4}$ using X-ray powder diffraction (XRD). The corresponding diffraction patterns can be found in Fig. S6 (ESI $\dagger)$; they show the $(00 l)$ peaks (only even values of $l$ for $\left.(\mathrm{PEA})_{2} \mathrm{CuCl}_{4}\right),{ }^{14,24}$ indicating that the inorganic plane is strongly oriented parallel to the substrate. No discernable new features were detected for the converted (PEA) ${ }_{2} \mathrm{CuCl}_{4}$ film compared to the pristine material. The same is true for $(\mathrm{MA})_{2} \mathrm{CuCl}_{4}$, as expected since there was no change in the absorbance spectrum after UV treatment.

In our previous work we have demonstrated that XRD is not always the best choice for detailed structural characterization of metal halide perovskites, and we showed that grazing-incidence wide-angle X-ray scattering (GIWAXS) could provide more details. $^{25}$ This is especially true if a texture is present in the perovskite layer. ${ }^{26}$ This advantage is combined with the ability to carry out depth-resolved measurements by varying the incident angle. ${ }^{27,28}$ Fig. 3 shows the GIWAXS patterns of the pristine and UV-treated (PEA) ${ }_{2} \mathrm{CuCl}_{4}$ films at two different incident angles, $\alpha_{i}=0.2^{\circ}$ and $0.8^{\circ}$, which correspond to roughly 25 and $2000 \mathrm{~nm}$ of X-ray penetration depth, respectively. The GIWAXS pattern of the pristine material (Fig. 3a and c) is composed of three strong signals focused along the quasivertical $\mathrm{q}_{z}$ direction related to the $(00 l)$ reflections, one strong
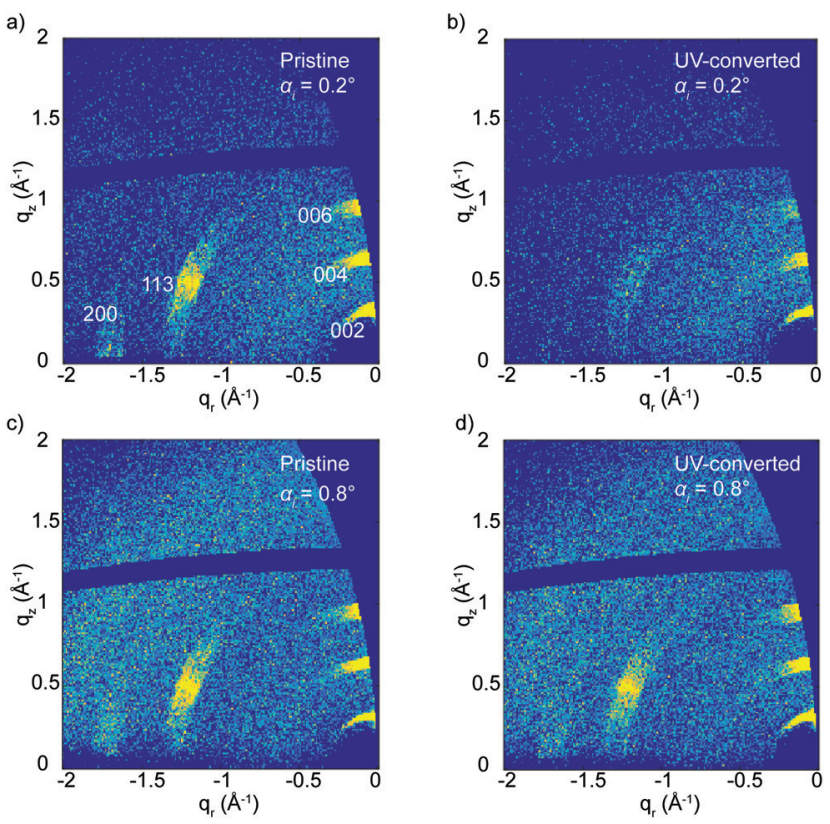

Fig. 3 Wedge corrected GIWAXS patterns for a thin film of $(P E A)_{2} \mathrm{CuCl}_{4}$ (a and $c$ ) before and ( $b$ and d) after UV irradiation measured at two different incident angles $\left(\alpha_{i}=0.2^{\circ}(\sim 25 \mathrm{~nm})\right.$ for $a$ and $b$ and $\alpha_{i}=0.8^{\circ}(\sim 2 \mu \mathrm{m})$ for $c$ and d). 
out-of-plane signal (113 reflection) and one weak signal along the $\mathrm{q}_{y}$ direction, related to a (h00) signal. The pattern can be indexed using the known crystallographic structure for (PEA) $\mathrm{CuCl}_{4}$, which is an orthorhombic unit cell of Pbca space group with axes of $7.31 \AA$, $7.34 \AA$ and $38.64 \AA(a \times b \times c) .{ }^{14}$ The anisotropic nature of the signals confirms the preferred orientation of the crystallites with the $(00 l)$ planes parallel to the substrate (see Fig. S7 (ESI $\dagger$ ) for more details). The intense $(00 l)$ reflections with respect to the much weaker out-of-plane reflections can be explained by a higher degree of ordering of the stacking planes in the vertical $z$-direction rather than in the $x y$-plane. This is probably a result of the Jahn-Teller effect in these compounds.

Upon illumination with UV light, the (113) and (200) reflections practically disappear and the $(00 l)$ reflections becomes approximately five times weaker, although they do not vanish (see Fig. 3b and Fig. S8, ESI $\dagger$ ). This indicates that UV treatment destroys the structural order in the $x y$-plane and reduces it in the $z$-direction. This effect is mostly limited to the top part of the film (top hundreds of $\mathrm{nm}$ ), as the GIWAXS patterns before and after irradiation change negligibly when full X-ray penetration of the film is achieved (Fig. $3 \mathrm{c}$ and d). We also looked at the effect of the color change from brown back to yellow induced by air exposure. After several hours in air, the GIWAXS pattern characteristic of the pristine film is fully recovered (see Fig. 4).

Due to the conversion taking place mainly at the surface of the thin film, we resorted to X-ray photoelectron spectroscopy (XPS) to study the surface composition of the film. The full XPS spectra are displayed in Fig. S9 (ESI $\dagger$ ). The $\mathrm{Cu} 2$ p XPS spectrum of the pristine (PEA) $)_{2} \mathrm{CuCl}_{4}$ film is shown in Fig. 5a. The fitted spectra of the other elements are included in the ESI $\dagger$ (Fig. S10). The film was UV-treated in the XPS setup under vacuum and measured afterwards. The UV-treatment was carried out for a cumulative duration of 45, 90 and 180 minutes. The satellite structures in Fig. 5a indicate the presence of $\mathrm{Cu}^{2+}$ species, as expected. ${ }^{29,30}$ As highlighted in Fig. 5b, there is an additional feature stemming from $\mathrm{Cu}^{0 /+}$, for which the oxidation states cannot be discriminated precisely. ${ }^{30}$ However, it is clear that the ratio of $\mathrm{Cu}^{2+}$ to $\mathrm{Cu}^{0 /+}$ decreases with $\mathrm{UV}$ exposure. Initially, $\mathrm{Cu}^{2+}$ and $\mathrm{Cu}^{0 /+}$ make up about $75 \%$ and $25 \%$ of the $\mathrm{Cu} 2 \mathrm{p}_{3 / 2}$ signal, respectively, while after 180 minutes of exposure the $\mathrm{Cu}^{2+}$ feature represents $43 \%$ of the $\mathrm{Cu} 2 \mathrm{p}_{3 / 2}$ component (see
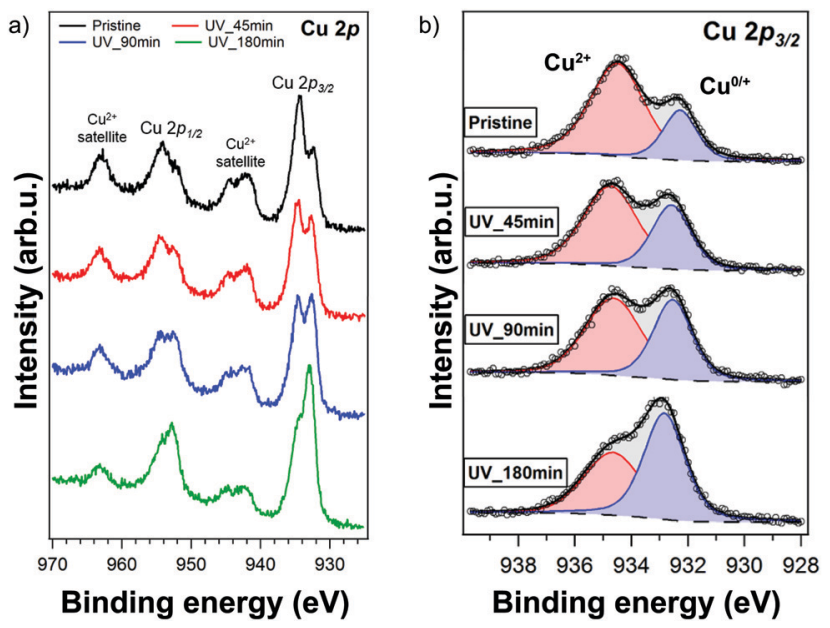

Fig. 5 (a) XPS spectra of the Cu $2 p$ core level region of a pristine $(P E A)_{2}$ $\mathrm{CuCl}_{4}$ film and after exposing it to UV light for various durations. The film was UV-converted in situ; XPS spectra were recorded after 45, 90 and 180 minutes. (b) Fits of the high-resolution $\mathrm{Cu} 2 \mathrm{p}_{3 / 2}$ peaks with $\mathrm{Cu}^{2+}$ (red curve) and $\mathrm{Cu}^{0 /+}$ (blue curve) signals for the different data depicted in (a).

Fig. S11, ESI $\dagger$ ). Additionally, the $\mathrm{Cl} / \mathrm{Cu}$ atomic ratio decreases from 5.0 in the initial measurement to 2.7 after 180 minutes of UV treatment (Fig. S12, ESI $\dagger$ ).

We carried out photoluminescence measurements on both the pristine and UV-converted films to see whether the $\mathrm{Cu}^{0 /+}$ led to new emission peaks. Laser excitation was performed at $267 \mathrm{~nm}$. The photoluminescence (PL) experiment was carried out at $5 \mathrm{~K}$, a temperature at which the conversion does not take place. Fig. 6 shows the PL intensity for both pristine and UV-converted $(\mathrm{PEA})_{2} \mathrm{CuCl}_{4}$. It is clear that the pristine material does not emit. However, the UV-converted film has a strong signal centered around $550 \mathrm{~nm}$. This is a very valuable finding for identification of the new species that form during the illumination of $(\mathrm{PEA})_{2} \mathrm{CuCl}_{4}$.

\section{Discussion}

From XPS we can conclude that UV-treatment of $(\mathrm{PEA})_{2} \mathrm{CuCl}_{4}$ results in the reduction of $\mathrm{Cu}^{2+}$ to $\mathrm{Cu}^{0 /+}$ (Fig. 5b). The copper reduction during UV irradiation is further confirmed by the decrease in satellite structures (Fig. 5a). The initial presence of
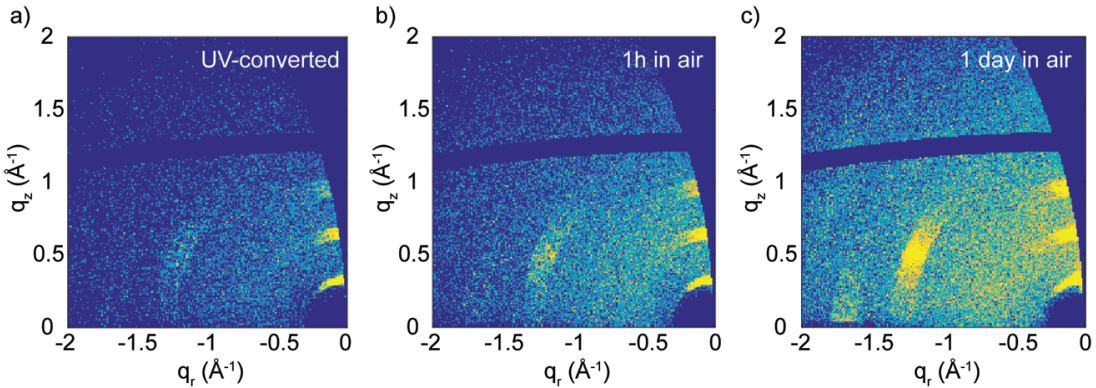

Fig. 4 Evolution of the GIWAXS patterns for the (PEA) ${ }_{2} \mathrm{CuCl}_{4}$ film in air (a) just after irradiation with UV light, (b) 1 hour after irradiation and (c) 1 day after irradiation. The incident angle was $0.2^{\circ}$. Note that the sample was kept in the same place during this measurement, to ensure that a quantitative comparison between the different images can be made. 
the $\mathrm{Cu}^{0 /+}$ component can be assigned to structural defects, partial reduction of $\mathrm{Cu}$ on the surface ${ }^{31,32}$ or traces of synthesis precursors. $^{31}$ The decrease in $\mathrm{Cl} / \mathrm{Cu}$ atomic ratio from 5.0 to 2.7 (Fig. S12, ESI $\dagger$ ) is a clear indication that copper is in a lower oxidation state. Consequently, the formation of new compounds with $\mathrm{Cu}$ in a lower oxidation state has to be taken into consideration. Since the XPS measurement cannot distinguish between the two oxidation states of the $\mathrm{Cu}^{0 /+}$ feature, both $\mathrm{Cu}^{+}$ and elemental copper could be formed in the process. Reports on the photoluminescence of $\mathrm{Cu}^{+}$typically show emission with a peak around $515 \mathrm{~nm},{ }^{18,33}$ while copper(I) chloride $(\mathrm{CuCl})$ emits around $390 \mathrm{~nm} .{ }^{34}$ Both cannot explain what we observe in our measurements (550 nm, Fig. 6). Therefore, we have to look for a different origin. Considering elemental copper, we find that copper nanoparticles (NPs) embedded in $\mathrm{a} \mathrm{SiO}_{2}$ matrix were reported to show photoluminescence around $550 \mathrm{~nm}$, depending on their size. ${ }^{35}$ Such metallic copper NPs have been demonstrated to form through photochemical reduction of $\mathrm{Cu}^{+}$ and $\mathrm{Cu}^{2+}$, by illuminating precursors - such as $\mathrm{CuCl}_{2}-$ in solution with UV light. ${ }^{36-39}$ An example of photoinduced formation of metallic nanoparticles in solid state is the reduction of $\mathrm{Au}(\mathrm{III})$ to $\mathrm{Au}(0)$ nanoparticles, which occurs when $\mathrm{AuCl}_{4}{ }^{-}$is exposed to UV light. ${ }^{40}$ The presence of copper NPs could also explain the broad feature in the absorbance (Fig. 1b) between 450 and $800 \mathrm{~nm} .{ }^{36}$ Another explanation for the broad absorption is the formation of $\mathrm{Cu}_{2} \mathrm{O}$ NPs. ${ }^{41}$ Considering that the conversion takes place in a nitrogen-filled glovebox, we deem the latter improbable.

A partial contribution to the broad absorption feature could also be attributed to the presence of square-planar $\mathrm{CuCl}_{4}{ }^{2-}$ species. The $\mathrm{CuCl}_{4}{ }^{2-}$ ion has a centrosymmetric planar geometry with $D_{4 \mathrm{~h}}$ symmetry; ${ }^{42}$ the inorganic plane of $(\mathrm{PEA})_{2} \mathrm{CuCl}_{4}$ can be seen as square-planar $\mathrm{CuCl}_{4}{ }^{2-}$ ions linked to form infinite layers - a sort of polymerization - with $\mathrm{Cu}-\mathrm{Cl}-\mathrm{Cu}$ bonds linking the ions. ${ }^{4}$ The absorbance spectrum of square-planar $\mathrm{CuCl}_{4}{ }^{2-}$ displays ligand-field transitions between 500 and $850 \mathrm{~nm} .^{43,44}$ The formation of $\mathrm{CuCl}_{4}{ }^{2-}$ can also explain the shift in the

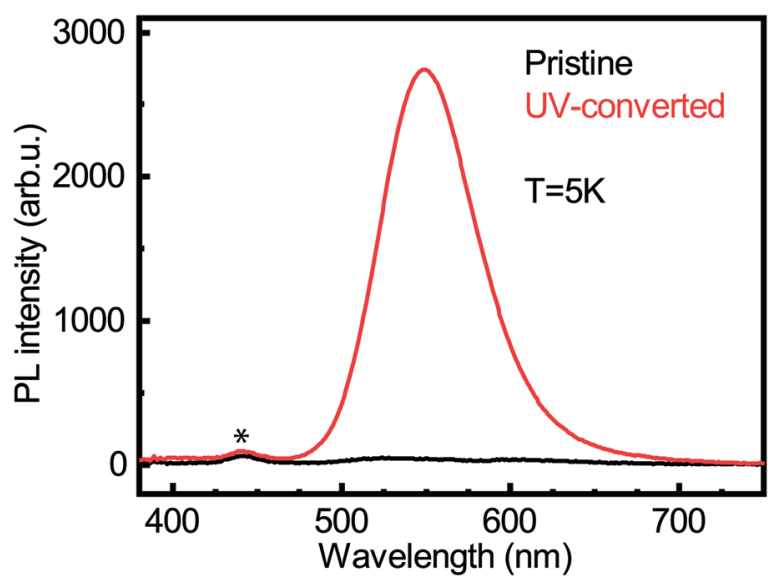

Fig. 6 Photoluminescence spectra for pristine (black line) and UV-converted (red line) (PEA) ${ }_{2} \mathrm{CuCl}_{4}$ films acquired at $5 \mathrm{~K}$. The peak that is marked with an asterisk is a measurement artifact due to stray background light.
UV-region of the absorption spectrum, because these ions have an absorption peak around $267-270 \mathrm{~nm}$, matching perfectly with our spectrum. ${ }^{45,46}$ In addition, the new Raman peak can be attributed to square-planar $\mathrm{CuCl}_{4}{ }^{2-}$ : the totally symmetric stretch of the ion is found at $271 \mathrm{~cm}^{-1} \cdot{ }^{43,47}$ Furthermore, there are reports in literature on a thermochromic effect in tetrachlorocuprates(II), where an increase in temperature leads to a (semi)reversible color change from green (square-planar $\mathrm{CuCl}_{4}{ }^{2-}$ ) to yellow $\left(\mathrm{CuCl}_{4}{ }^{2-}\right.$ in the form of a distorted tetrahedron). ${ }^{9,48}$ For bis(piperazinium) tetrachlorocuprate this effect also occurs upon illumination. ${ }^{9}$ In our case, the effect would involve a change from octahedral to square-planar $\mathrm{CuCl}_{4}{ }^{2-}$, which would mean that the connected square-planar $\mathrm{CuCl}_{4}{ }^{2-}$ ions would become isolated. A similar process has been reported as a thermal effect in a hydrated nickel bromide compound. ${ }^{49}$ It is also important to underline that the transition from octahedral to square-planar $\mathrm{CuCl}_{4}{ }^{2-}$ could explain the disorder in the $x y$-plane, which was demonstrated with GIWAXS (see Fig. $3 \mathrm{~b}$ ).

The absorbance spectrum of UV-treated $(\mathrm{PEA})_{2} \mathrm{CuCl}_{4}$ still shows features from the pristine layer in the form of a shoulder at $291 \mathrm{~nm}$ (see Fig. 1b). This can be explained by the results of the GIWAXS experiment, where we found that the conversion occurs in the first hundreds of nanometers from the surface. Below, in the bulk of the layer, no conversion takes place. This is the result of the limited penetration depth of UV light in our material. Therefore, the light can only convert (PEA) ${ }_{2} \mathrm{CuCl}_{4}$ in the first hundreds of nanometers.

Air exposure leads to the color change from brown to yellow. Bhattacharya et al. found that the thermochromic bis(benzimidazolium) tetrachlorocuprate can exist in two forms: the yellow non-hydrated phase and a green hydrated phase. ${ }^{11}$ The former consists of isolated distorted tetrahedral $\mathrm{CuCl}_{4}{ }^{2-}$ ions, the latter has alternating polymeric $\left[\mathrm{CuCl}_{4}{ }^{2-}\right]_{\infty}$ and $\left[\mathrm{CuCl}_{2}\left(\mathrm{H}_{2} \mathrm{O}\right)_{2}\right]_{\infty}$ chains. $^{50}$ Upon heating, the green hydrated phase loses the water molecules due to a thermochromic transition. The resulting yellow phase has isolated $\mathrm{CuCl}_{4}{ }^{2-}$ ions. The authors also demonstrated the reverse process, where the non-hydrated compound absorbs water to form the polymeric $\left[\mathrm{CuCl}_{2}\left(\mathrm{H}_{2} \mathrm{O}\right)_{2}\right]_{\infty}$ chains. $^{50}$ Therefore, their system is a good example of a monomeric - polymeric transformation based on thermochromism and exposure to water molecules. We suppose that the mechanism behind the color change back to yellow in air for our system works in an analogous way, i.e. the square-planar $\mathrm{CuCl}_{4}{ }^{2-}$ ions in the brown phase could change to alternating polymeric $\left[\mathrm{CuCl}_{4}{ }^{2-}\right]_{\infty}$ and $\left[\mathrm{CuCl}_{2}\left(\mathrm{H}_{2} \mathrm{O}\right)_{2}\right]_{\infty}$ chains after absorbing water molecules from the air. This would look more similar to the structure of pristine $(\mathrm{PEA})_{2} \mathrm{CuCl}_{4}$ and could explain the recovery of the (113) and (200) reflections in the GIWAXS experiment due to the longer structural order of the polymeric chains.

At this point we are left to explain the lack of photochromic behavior in (MA) ${ }_{2} \mathrm{CuCl}_{4}$ (see Fig. 1c). We propose that this is due to a difference in the strength of the hydrogen bonding between the organic cation and the halide ions. Bloomquist et al. studied the thermochromic change of bis(isopropylammonium) tetrachlorocuprate and found that this involves 
a change from a linear structure of ribbon-like connected square-planar $\mathrm{CuCl}_{4}{ }^{2-}$ to isolated distorted tetrahedral $\mathrm{CuCl}_{4}{ }^{2-} \cdot{ }^{10}$ This is caused by a weakened hydrogen bond between the organic cations and the chloride ions due to an increase in temperature. Without the hydrogen bond there is an excess electrostatic charge on the chloride ions, which leads to a relaxation of the coordination of the copper complex to a distorted tetrahedral structure. The $\mathrm{CH}_{3}$-group in MA has an electron donating character, whereas the phenyl ring in PEA is electron withdrawing. This might lead to a difference in hydrogen bonding strength and stability of the octahedral structure. Additionally, methylamine does not absorb $254 \mathrm{~nm}$ light, whereas phenethylamine does. ${ }^{51,52}$ This means that only PEA will be in an excited state upon illumination. It has been shown that the most stable conformer of phenethylammonium has a gauche confirmation of the $\mathrm{NH}_{3}{ }^{+}$-group with respect to the alkyl chain, in which one hydrogen atom of the $\mathrm{NH}_{3}{ }^{+}$-group is oriented towards the benzene ring. ${ }^{53}$ In the excited state of this molecule, this hydrogen atom is situated closer to the benzene ring. ${ }^{54}$ Therefore, UV illumination could weaken the hydrogen bonding between PEA and the chloride ions.

\section{Conclusions}

This work is the first report on the photochromic properties of the hybrid organic-inorganic Ruddlesden-Popper perovskite (PEA $)_{2} \mathrm{CuCl}_{4}$. Exposure to UV light $(\lambda=254 \mathrm{~nm})$ in a nitrogen environment leads to a color change of the film from yellow to brown, but the color change can also occur in other conditions (312 $\mathrm{nm}$ light in air). This is accompanied by a loss in structural order in the $x y$-plane of the film's surface, as determined by GIWAXS. X-ray photoelectron spectroscopy shows that UV illumination causes the reduction of $\mathrm{Cu}^{2+}$ to $\mathrm{Cu}^{0 /+}$. As a result of the illumination, new features were found in the absorbance and Raman spectra of UV-converted (PEA) ${ }_{2} \mathrm{CuCl}_{4}$, which can be explained by the presence of square-planar $\mathrm{CuCl}_{4}{ }^{2-}$ species. The instability of UV-converted (PEA) ${ }_{2} \mathrm{CuCl}_{4}$ in air is demonstrated by a color change back to yellow, which is accompanied by a recovery of the structural order, as seen in the GIWAXS pattern. The similar compound $(\mathrm{MA})_{2} \mathrm{CuCl}_{4}$ does not show photochromic behavior, which we attribute to a difference in hydrogen bond strength between the organic cation and the chloride anions due to the different chemical nature of the two organic cations.

\section{Experimental section}

\section{Film processing}

Preparing and spin coating the metal halide perovskite solutions took place in a glovebox with nitrogen environment. A solution of $(\mathrm{PEA})_{2} \mathrm{CuCl}_{4}$ was made by dissolving phenethylammonium chloride (Sigma Aldrich) and copper(II) chloride (Sigma Aldrich) in $N, N$ dimethylformamide (DMF, Sigma Aldrich) in a 2:1 molar ratio. The final concentration of the solution was $1 \mathrm{M}$. For $(\mathrm{MA})_{2} \mathrm{CuCl}_{4}$, methylammonium chloride (Sigma Aldrich) was used instead.
Here, two solvents, DMF and dimethyl sulfoxide (DMSO, Alfa Aesar), were used in a $4: 1 \mathrm{v} / \mathrm{v}$ ratio to improve the solubility. This solution had a $0.8 \mathrm{M}$ concentration. Solutions were stirred at room temperature overnight before spin coating. The substrates were either made of glass or quartz and were cleaned with detergent solution, and subsequently ultrasonically cleaned in deionized water, acetone and isopropanol. After drying them in an oven at $130{ }^{\circ} \mathrm{C}$ for $10 \mathrm{~min}$, they were treated with ultraviolet ozone $\left(\mathrm{UV}-\mathrm{O}_{3}\right)$ for $20 \mathrm{~min}$. Spin coating involved a rotation of $5000 \mathrm{rpm}$ during 45 seconds for $(\mathrm{PEA})_{2} \mathrm{CuCl}_{4}$ and $3000 \mathrm{rpm}$ for $(\mathrm{MA})_{2} \mathrm{CuCl}_{4}$. To prevent charging effects in the XPS experiment we made a very thin film (50-150 nm) on a silicon substrate. This was done by blade coating because it offered us better control over the morphology of a very thin film compared to spin coating. For this experiment, the (PEA) ${ }_{2} \mathrm{CuCl}_{4}$ solution was diluted to $0.1 \mathrm{M}$ and this was coated at $120{ }^{\circ} \mathrm{C}$ with a blade speed of $40 \mathrm{~mm} \mathrm{~s}^{-1}$.

\section{Crystal synthesis}

Single crystals of (PEA $)_{2} \mathrm{CuCl}_{4}$ were grown by the slow evaporation of solvent at $60{ }^{\circ} \mathrm{C}$. A 1:2 molar ratio of $\mathrm{CuCl}_{2} \cdot 2 \mathrm{H}_{2} \mathrm{O}$ (Sigma Aldrich; $\geq 99.95 \%$ ) and $\mathrm{C}_{6} \mathrm{H}_{5} \mathrm{CH}_{2} \mathrm{CH}_{2} \mathrm{NH}_{2} \cdot \mathrm{HCl}$ (Sigma Aldrich; $\geq 98 \%$ ) were dissolved in absolute ethanol (J.T. Baker) and placed in an oven at $60{ }^{\circ} \mathrm{C}$. After approximately one week, transparent, yellow single crystals had formed. The crystals are shaped as platelets with sizes ranging from 0.1 to around $6 \mathrm{~mm}$.

\section{UV treatment}

For the UV treatment the $\lambda=254 \mathrm{~nm}$ setting of a Spectroline EBF-280C/FE lamp was used. The UV treatment was carried out in a $\mathrm{N}_{2}$-filled glovebox for 45 minutes. The distance from the lamp to the sample was approximately $15 \mathrm{~mm}$. For the experiment with the $\lambda=312 \mathrm{~nm}$ UV source, the longer wavelength setting on the same lamp was used.

\section{Absorbance}

The thin film samples for the absorbance measurement were made on quartz, and characterized with a Shimadzu UV-3600 spectrophotometer with an integrating sphere attachment.

\section{X-Ray diffraction}

Powder XRD data were collected under ambient conditions using a Bruker D8 Advance diffractometer in Bragg-Brentano geometry and operating with $\mathrm{Cu} K \alpha$ radiation $(\lambda=1.54 \AA)$. A fixed slit width was used for the incident beam $(1 \mathrm{~mm})$ and diffracted beam $(3 \mathrm{~mm})$. Samples were rotated at 60 revolutions per minute. The angle $2 \theta$ was scanned between 5 and 40 degrees using a 0.015 degrees step size.

\section{Grazing-incidence wide-angle X-ray scattering}

GIWAXS experiments were performed at the Multipurpose Instrument for Nanostructured Analysis (MINA) at RUG. The instrument is equipped with a rotating $\mathrm{Cu}$ anode source $(\lambda=0.15413 \mathrm{~nm})$. GIWAXS patterns were acquired using a Pilatus $300 \mathrm{~K}$ solid state detector from Dectris with pixel size $0.172 \mathrm{~mm} \times 0.172 \mathrm{~mm}$. The sample alignment and the incident angle setting were achieved using motorized Huber positioning 
stages. The sample-to-detector distance (S-to-D) and the position of the direct beam on the detector where calibrated using known diffraction peaks from a silver behenate standard sample. The calibrated S-to-D value was $90 \mathrm{~mm}$. The missing wedge correction and the intensity line cuts were obtained using the GIXGUI software. $^{55}$ In the case of an ideally flat surface, the X-ray penetration depth (i.e. the depth into the material measured along the surface normal where the intensity of X-rays falls to $1 / e$ of its value at the surface) depends on the wavelength $\lambda$ of the X-rays, the critical angle of total reflection, $\alpha_{c}$, and the incident angle, $\alpha_{i}$, and can be estimated using the relation: $\Lambda=\frac{\lambda}{4 \pi} \sqrt{\frac{2}{\left(\alpha_{i}^{2}-\alpha_{c}^{2}\right)^{2}+4 \beta^{2}-\left(\alpha_{i}^{2}-\alpha_{c}^{2}\right)}}$, where $\beta$ is the imaginary part of the complex refractive index of the compound.

\section{X-ray photoelectron spectroscopy}

XPS was performed using a Surface Science SSX-100 ESCA instrument with a monochromatic $\mathrm{Al} \mathrm{K} \alpha \mathrm{X}$-ray source $(h v=$ $1486.6 \mathrm{eV}$ ). The pressure in the measurement chamber was maintained below $1 \times 10^{-9}$ mbar during data acquisition. The electron take-off angle with respect to the surface normal was $37^{\circ}$. The XPS data were acquired by using a spot size of $1000 \mu \mathrm{m}$ diameter and the energy resolution was set to $1.3 \mathrm{eV}$ for both the survey spectra and the detailed spectra of the $\mathrm{C} 1 \mathrm{~s}, \mathrm{Cl} 2 \mathrm{p}, \mathrm{Cu}$ 2 p, N 1s and O 1s core level regions. Furthermore, a gold mesh placed $1 \mathrm{~mm}$ above the sample was used during the XPS measurements in order to prevent the charging effect. Binding energies are reported $\pm 0.1 \mathrm{eV}$ and referenced to the $\mathrm{C} 1 \mathrm{~s}$ photoemission peak centered at a binding energy of $284.8 \mathrm{eV}{ }^{56}$ All XPS spectra were analyzed using the least-squares curve fitting program Winspec (LISE laboratory, University of Namur, Belgium). Deconvolution of the spectra included a Shirley ${ }^{57}$ baseline subtraction and fitting with a minimum number of peaks consistent with the structure of the components of the thin film, taking into account the experimental resolution. The profile of the peaks was taken as a convolution of Gaussian and Lorentzian functions. The uncertainty in the peak intensity determination is within $2 \%$ for all core levels reported. All measurements were carried out on freshly prepared samples. Exposure to UV (254 nm) light was conducted in situ through a special window of the vacuum chamber.

\section{Raman spectroscopy}

Raman spectroscopy was carried out using a confocal inVia Qontor micro-Raman setup from Renishaw. Excitation occurred at $532 \mathrm{~nm}$ through a $50 \times$ objective, with a power between 39.5 and $73.4 \mu \mathrm{W}$. The light was collected in backscattering geometry, dispersed with a 2400 lines per millimeter grating and detected with a silicon CCD. Spectral calibration was assured through a silicon reference.

\section{Photoluminescence spectroscopy}

For low-temperature photoluminescence spectroscopy, thin films were mounted into a cryostat (Oxford Instruments Optistat CF) in an inert atmosphere. The samples were excited at $4.6 \mathrm{eV}(267 \mathrm{~nm})$ using the third harmonic of a mode-locked Ti:sapphire laser (Mira 900, Coherent) operating at a repetition rate of $76 \mathrm{MHz}$. The excitation beam was spatially limited by an iris and focused onto the sample using a $150 \mathrm{~mm}$ focal length lens in a reflection geometry. The pump fluence was controlled using an adjustable neutral density filter. The photoluminescence was collected into a spectrometer and recorded by an ImagEM CCD camera (Hamamatsu, Japan).

\section{Author contribution statement}

B. G., H. D. and M. A. L. designed the experiments. B. G., L. P. and M. A. L. conceived of the presented idea and crucial parts of the interpretation. H. D. carried out the photoluminescence experiment. S. K. was responsible for the Raman spectroscopy. The X-ray photoelectron spectroscopy experiment was carried out and analyzed by O. D. L. and P. R. X-ray diffraction characterization was conducted by E. T. and G. B. M. K. synthesized the single crystals. G. P. carried out the grazing-incidence wide-angle X-Ray scattering experiment and analysis. B. G. was responsible for all other experiments, made the thin film samples and wrote the manuscript. All authors provided critical feedback and helped writing the manuscript.

\section{Conflicts of interest}

There are no conflicts to declare.

\section{Acknowledgements}

The authors are thankful to A. Kamp and T. Zaharia for technical support. This work is part of the research program of the Netherlands Organisation for Scientific Research (NWO). This is a publication of the FOM-focus Group 'Next Generation Organic Photovoltaics', participating in the Dutch Institute for Fundamental Energy Research (DIFFER). Financial support also came from the Advanced Materials research program of the Zernike National Research Centre under the Bonus Incentive Scheme (BIS) of the Dutch Ministry for Education, Culture and Science. S. K. acknowledges the Deutsche Forschungsgemeinschaft (DFG) for a postdoctoral research fellowship (grant no. 408012143).

\section{References}

1 D. B. Mitzi, Progress in Inorganic Chemistry, 1999, vol. 48, pp. 1-121.

2 D. B. Mitzi, J. Chem. Soc., Dalton Trans., 2001, 1-12.

3 H. Place and R. D. Willett, Acta Crystallogr., Sect. C: Cryst. Struct. Commun., 1988, 44, 34-38.

4 D. W. Smith, Coord. Chem. Rev., 1976, 21, 93-158.

5 R. D. Willett, J. A. Haugen, J. Lebsack and J. Morrey, Inorg. Chem., 1974, 13, 2510-2513.

6 L. L. Lohr, Proc. Natl. Acad. Sci. U. S. A., 1968, 59, 720-725.

7 A. Jaffe, Y. Lin, W. L. Mao and H. I. Karunadasa, J. Am. Chem. Soc., 2015, 137, 1673-1678. 
8 P. Ghalsasi, N. Garg, M. N. Deo, A. Garg, H. Mande, P. Ghalsasi and S. M. Sharma, Phys. Chem. Chem. Phys, 2015, 17, 32204-32210.

9 M. J. Riley, D. Neill, P. V. Bernhardt, K. A. Byriel and C. H. L. Kennard, Inorg. Chem., 1998, 37, 3635-3639.

10 D. R. Bloomquist, R. D. Willett and H. W. Dodgen, J. Am. Chem. Soc., 1981, 103, 2610-2615.

11 R. Bhattacharya, M. Sinha Ray, R. Dey, L. Righi, G. Bocelli and A. Ghosh, Polyhedron, 2002, 21, 2561-2565.

12 K. Sone and Y. Fukuda, Inorganic Thermochromism, 1987, pp. 104-131.

13 M. R. Bond, T. J. Johnson and R. D. Willett, Can. J. Chem., 1988, 66, 963-973.

14 A. Caretta, R. Miranti, A. H. Arkenbout, A. O. Polyakov, A. Meetsma, R. Hidayat, M. O. Tjia, T. T. M. Palstra and P. H. M. van Loosdrecht, J. Phys.: Condens. Matter, 2013, 25, 505901.

15 D. Xie, J. Xu, H. Cheng, N. Wang and Q. Zhou, J. Mol. Struct., 2018, 1161, 267-272.

16 X. Pan, G. Wu, M. Wang and H. Chen, J. Zhejiang Univ., Sci., A, 2009, 10, 710-715.

17 A. O. Polyakov, A. H. Arkenbout, J. Baas, G. R. Blake, A. Meetsma, A. Caretta, P. H. M. Van Loosdrecht and T. T. M. Palstra, Chem. Mater., 2012, 24, 133-139.

18 D. Cortecchia, H. A. Dewi, J. Yin, A. Bruno, S. Chen, T. Baikie, P. P. Boix, M. Grätzel, S. Mhaisalkar, C. Soci and N. Mathews, Inorg. Chem., 2016, 55, 1044-1052.

19 R. G. McDonald and M. A. Hitchman, Inorg. Chem., 1989, 28, 3996-4001.

20 A. Dick, H. Rahemi, E. R. Krausz, G. R. Hanson and M. J. Riley, J. Chem. Phys., 2008, 129, 214505.

21 M. J. Riley, C. Boutchard, E. R. Krausz and M. A. Hitchman, Chem. Phys. Lett., 1996, 254, 403-409.

22 A. Caretta, R. Miranti, R. W. A. Havenith, E. Rampi, M. C. Donker, G. R. Blake, M. Montagnese, A. O. Polyakov, R. Broer, T. T. M. Palstra and P. H. M. van Loosdrecht, Phys. Rev. B: Condens. Matter Mater. Phys., 2014, 89, 024301.

23 I. Pabst, J. Karolyi, H. Fuess and M. Couzi, Phys. Status Solidi, 1996, 155, 341-352.

24 I. Pabst, H. Fuess and J. W. Bats, Acta Crystallogr., Sect. C: Cryst. Struct. Commun., 1987, 43, 413-416.

25 B. G. H. M. Groeneveld, S. Adjokatse, O. Nazarenko, H.-H. Fang, G. R. Blake, G. Portale, H. Duim, G. H. ten Brink, M. V. Kovalenko and M. A. Loi, Energy Technol., 2019, 1901041.

26 S. Shao, J. Liu, G. Portale, H.-H. Fang, G. R. Blake, G. H. ten Brink, L. J. A. Koster and M. A. Loi, Adv. Energy Mater., 2018, 8, 1702019.

27 J. Dong, S. Shao, S. Kahmann, A. J. Rommens, D. HermidaMerino, G. H. ten Brink, M. A. Loi and G. Portale, Adv. Funct. Mater., 2020, 30, 2001294.

28 A. Vagias, Q. Chen, G. H. ten Brink, D. Hermida-Merino, J. Scheerder and G. Portale, ACS Appl. Polym. Mater., 2019, 1, 2482-2494.

29 F. Gao, Y. Wang, X. Wang and S. Wang, RSC Adv., 2016, 6, 34439-34446.
30 W.-L. Dai, Q. Sun, J.-F. Deng, D. Wu and Y.-H. Sun, Appl. Surf. Sci., 2001, 177, 172-179.

31 S. K. Abdel-Aal, G. Kocher-Oberlehner, A. Ionov and R. N. Mozhchil, Appl. Phys. A: Mater. Sci. Process., 2017, 123, 531.

32 N. Akhtar, G. R. Blake, R. Felici, H. Amenitsch, T. T. M. Palstra and P. Rudolf, Nano Res., 2014, 7, 1832-1842.

33 S. Gomez, I. Urra, R. Valiente and F. Rodriguez, J. Phys.: Condens. Matter, 2010, 22, 295505.

34 M. Nakayama, H. Ichida and H. Nishimura, J. Phys.: Condens. Matter, 1999, 11, 7653-7662.

35 O. A. Yeshchenko, I. M. Dmitruk, A. M. Dmytruk and A. A. Alexeenko, Mater. Sci. Eng., B, 2007, 137, 247-254.

36 X. Zhu, B. Wang, F. Shi and J. Nie, Langmuir, 2012, 28, 14461-14469.

37 G. G. Condorelli, L. L. Costanzo, I. L. Fragalà, S. Giuffrida and G. Ventimiglia, J. Mater. Chem., 2003, 13, 2409-2411.

38 S. Giuffrida, G. G. Condorelli, L. L. Costanzo, I. L. Fragalà, G. Ventimiglia and G. Vecchio, Chem. Mater., 2004, 16, 1260-1266.

39 B. Wang, S. Chen, J. Nie and X. Zhu, RSC Adv., 2014, 4, 27381-27388.

40 A. Taubert, I. Arbell, A. Mecke and P. Graf, Gold Bull., 2006, 39, 205-211.

41 S. Banerjee and D. Chakravorty, Europhys. Lett., 2000, 52, 468-473.

42 R. G. McDonald, M. J. Riley and M. A. Hitchman, Inorg. Chem., 1988, 27, 894-900.

43 A. Dick, H. Rahemi, E. R. Krausz, G. R. Hanson and M. J. Riley, J. Chem. Phys., 2008, 129, 214505.

44 M. A. Hitchman and P. J. Cassidy, Inorg. Chem., 1979, 18, 1745-1754.

45 S. R. Desjardins, K. W. Penfield, S. L. Cohen, R. L. Musselman and E. I. Solomon, J. Am. Chem. Soc., 1983, 105, 4590-4603.

46 H.-B. Yi, F.-F. Xia, Q. Zhou and D. Zeng, J. Phys. Chem. A, 2011, 115, 4416-4426.

47 V. M. Masters, M. J. Riley and M. A. Hitchman, Chem. Phys. Lett., 1998, 288, 743-748.

48 R. L. Harlow, W. J. Wells, G. W. Watt and S. H. Simonsen, Inorg. Chem., 1974, 13, 2860-2864.

49 R. Tsuchiya, S. Joba, A. Uehara and E. Kyuno, Bull. Chem. Soc. Jpn., 1973, 46, 1454-1456.

50 M. Bukowska-Strzyżewska and J. Skoweranda, Acta Crystallogr., Sect. C: Cryst. Struct. Commun., 1987, 43, 2290-2293.

51 L. Lagesson-Andrasko, V. Lagesson and J. Andrasko, Anal. Chem., 1998, 70, 819-826.

52 S. Sugasawa and R. Tachikawa, Tetrahedron, 1958, 4, 205-212. 53 J. J. Urban, C. W. Cronin, R. R. Roberts and G. R. Famini, J. Am. Chem. Soc., 1997, 119, 12292-12299.

54 G. Féraud, M. Broquier, C. Dedonder-Lardeux, G. Grégoire, S. Soorkia and C. Jouvet, Phys. Chem. Chem. Phys., 2014, 16, 5250.

55 Z. Jiang, J. Appl. Crystallogr., 2015, 48, 917-926.

56 J. F. Moulder, W. F. Stickle, P. E. Sobol and K. D. Bomben, Handbook of X-ray photoelectron spectroscopy: a reference book of standard spectra for identification and interpretation of XPS data, Physical Electronics Division, PerkinElmer Corp., 1992.

57 D. A. Shirley, Phys. Rev. B: Solid State, 1972, 5, 4709-4714. 